Article

\title{
Synthesis and Characterization of Functionalized Nanosilica for Zinc Ion Mitigation; Experimental and Computational Investigations
}

\author{
Zarshad Ali ${ }^{1}$, Rashid Ahmad ${ }^{2,3}$, W. Aslam Farooq ${ }^{4, *}$ (), Aslam Khan ${ }^{3}$, Adnan Ali Khan ${ }^{2}$ (D), \\ Saira Bibi ${ }^{1}$, Bushra Adalat ${ }^{1}$, Mona A. Almutairi ${ }^{4}$, Nafeesah Yaqub ${ }^{4}$ and Muhammad Atif ${ }^{4}$ \\ 1 Department of Chemistry, Hazara University, Mansehra 21300, Khyber Pakhtunkhwa, Pakistan; \\ Zarshad11@yahoo.com (Z.A.); sairabushi@gmail.com (S.B.); bushraadalat@yahoo.com (B.A.) \\ 2 Department of Chemistry, University of Malakand, Chakdara 18800, Dir Lower, Pakistan; \\ rashmad@gmail.com (R.A.); aak95287@gmail.com (A.A.K.) \\ 3 Chemistry Division, PINSTECH, PO Nilore 45650, Islamabad, Pakistan; jasminesi2007@gmail.com \\ 4 Department of Physics, College of Science, King Saud University, Riyadh 11451, Saudi Arabia; \\ 436204157@student.ksu.edu.sa (M.A.A.); na-foo-sah@hotmail.com (N.Y.); muhatif@KSU.EDU.SA (M.A.) \\ * Correspondence: awazirzada@ksu.edu.sa
}

Received: 4 November 2020; Accepted: 19 November 2020; Published: 25 November 2020

\begin{abstract}
Zinc is an essential trace metal and its concentration above 4ppm reduces the aesthetic value of water. This study explores the possibility of using functionalized nanohybrids as $\mathrm{Zn}$ (II) ion scavengers from aqueous solution. Functionalized nanohybrids were synthesized by the attachment of thiosemicarbazide to silica. The material was characterized by TGA, SEM, FTIR, EDX, and BET analysis, which revealed ligand bonding to silica. The functionalized silica was employed as $\mathrm{Zn}$ (II) ion extractant in batch experiments and removed about $94.5 \%$ of the $\mathrm{Zn}$ (II) ions at $\mathrm{pH}$, near zero point charge (6.5) in $30 \mathrm{~min}$. Kinetics investigations revealed that zinc adsorption follows an intra particle diffusion mechanism and first-order kinetics $\left(\mathrm{K}=0.1020 \mathrm{~min}^{-1}\right)$. The data were fitted to Freundlich, Dubinin-Radushkevich, and Langmuir models and useful ion exchange parameters were determined. The impact of co-existing ions on $\mathrm{Zn}$ (II) ion sequestration was also studied and it was found that the adsorbent can be used for selective removal of zinc with various ions in the matrix. Quantum mechanical investigations revealed that the $\mathrm{Zn}(\mathrm{II})$ ion adsorption on ZnBS1 is more favorable, having higher binding energy (BE) $(-178.1 \mathrm{kcal} / \mathrm{mol})$ and $\Delta H(-169.8)$, and making tridentate complex with the $\mathrm{N}$ and $\mathrm{S}$ sites of the chelating ligand. The negative $\Delta \mathrm{G}$ and $\mathrm{BE}$ values suggest highly spontaneous $\mathrm{Zn}(\mathrm{II})$ adsorption on the modified silica even at low temperatures.
\end{abstract}

Keywords: zinc adsorption; functionalized silica; adsorption models; surface modification; radiotracer; DFT analysis

\section{Introduction}

Mining operations and widespread industrial applications of metals have led to an increased level of toxic heavy metals in the environment and is one of the most threatening issues of the modern world. The levels of metals in the environment [1,2] are higher than their recommended levels, which impose a severe threat to humans and other organisms [3]. The selective extraction of these metals from wastewaters, such as mining/industrial and seawater, has been a goal of researchers for the purpose of water purification, metallurgical extraction, and environmental remediation $[4,5]$. A number of solid-phase extractants have been employed for adsorption of heavy metals from waste and drinking water. These materials include clay [6], zeolite [7], activated carbons [8], ion exchangers [9], and polyurethane foam [10], etc. Some of them suffer from inherent limitations, such as low efficiencies, 
poor selectivity, and chemical and mechanical instabilities. To minimize these problems, the idea of chemical functionalization have gained popularity and a number of functionalized organic inorganic hybrids were prepared [11,12]. In this context, functionalized silica gained attention for use in many technological applications, such as sensors, separation, medicines, and catalysis. These porous adsorbents have high surface areas, tunable morphologies, and good chemical and mechanical stabilities. These materials have been widely used for water purification and have excellent adsorption capacities and selectivity $[13,14]$.

Zinc is an essential metal for life as a co-factor for some enzyme and insulin production. Zinc and its compounds are of particular importance in steel coating, dry batteries, catalysts, plastics, ceramics, printing, and pharmacy and are also considered as a micro-nutrient for animals and plants. In surface and ground water, its level never exceeds 0.01 and $0.05 \mathrm{mg} / \mathrm{L}$ [15]. Above the permissible limit, zinc is harmful, due to its non-biodegradability and accumulation in the food chain and when its concentration exceeds $3 \mathrm{mg} / \mathrm{L}$ in water, it has a stringent taste, and hence, reduces its acceptability and aesthetic value [16]. Therefore, keeping the zinc concentration within acceptable limits in water is very much necessary [3]. This may be attained by conventional methods like chemical precipitation, membrane techniques, filtration, reverse osmosis, solvent extraction, and adsorption [17].

Although there are some reports of zinc extraction from aqueous solutions on functionalized silica [18-20], the zinc-retaining capability of these adsorbents was very low $(0.0011-1.59 \mathrm{mmol} / \mathrm{g})$. Furthermore, a great deal of adsorbents in the literature deal with the extraction of zinc in the presence of other co-existing metals and comprehensive reports of zinc uptake on the functionalized silica are relatively rare.

Keeping this and the economic importance of zinc in mind, we synthesized and characterized functionalized silica for the recovery of low-level zinc from solutions. The batch adsorption mode was employed for the quantitative determination of zinc in aqueous solutions. The effects of various parameters, such as the $\mathrm{pH}$, adsorption time, zinc(II) concentration, temperature, and quantity of functionalized silica adsorbent, were explored in detail. The $\mathrm{Zn}$ (II) adsorption optimum conditions were determined and the results were modelled with adsorption models, such as Langmuir, Freundlich, and Dubinin-Radushkevich (D-R). The mechanism of adsorption responsible for the binding of $\mathrm{Zn}$ (II) to the adsorbent surface was explored and discussed. The kinetics of $\mathrm{Zn}$ (II) adsorption were exhaustively studied to investigate the nature of the diffusion and kinetic order of $\mathrm{Zn}$ (II) adsorption. The $\mathrm{Zn}$ (II) extraction was also studied in the presence of competing ions in the matrix to ascertain the selectivity of silica adsorbent for zinc extraction. Regeneration studies were also performed to ensure the recyclability of the adsorbent and reversible binding of $\mathrm{Zn}$ (II) to the adsorbent surface. Furthermore, the computational method was also used as a suitable tool for the investigation of the molecular properties of various systems and understanding the geometries, electronic structures, and coordination modes [18-21]. The binding modes of thiosemicarbazide ligand with $\mathrm{Zn}$ (II) ions using computational tools for the adsorption of $\mathrm{Zn}(\mathrm{II})$ ions on various sites of chelating ligand were also investigated by computing binding energies and thermodynamic parameters.

\section{Materials and Methods}

\subsection{Chemical and Methods}

The chemical used were of analytical grade and were used as obtained. Tetraethylorthosilicate $97 \%$ was used as the silica source and was acquired from Sigma Aldrich, St. Louis, MO, USA. Cetyltrimethylammonium bromide (CTAB) was used as the templating agent and was acquired from Sigma Aldrich. The linker 3-aminopropyltrimethoxy silane (3-APTMS) and sodium hydroxide ( $\mathrm{NaOH})$ were also provided by Sigma Aldrich, St. Louis, MO, USA. Thiosemicarbazide was provided by East Man (Dresden, Germany). The water used was de-ionized, distilled from potassium permanganate pyres still. 
The $\mathrm{Zn}(\mathrm{II})$ radiotracer was prepared by neutron irradiation of pure zinc metal. In total, $20 \mathrm{mg}$ of zinc metal were encapsulated in a tube and coated with aluminum. The metal was then exposed to a constant neutron activation of $5 \times 10^{3} \mathrm{n} \cdot \mathrm{cm}^{-2} \mathrm{~s}^{-1}$ of neutrons in a $10 \mathrm{Mw}$ research reactor of PINSTECH Islamabad for $10 \mathrm{~h}$. The irradiated sample was kept for one week to cool down. After cooling, the sample was dissolved in conc. $\mathrm{HCl}$. Excessive acid was evaporated after repeated dilution with de-ionized water and heating to dryness. Finally, the radiotracer sample was diluted to $25 \mathrm{~mL}$ to make the stock solution. The radiotracer purity of the $\mathrm{Zn}$ (II) tracer was confirmed by a multichannel analyzer fitted with a germanium lithium detector (Canberra). Buffer solution of pH 1-8 was prepared by adding an appropriate volume of 0.1 molar $\mathrm{HCl}$ and $\mathrm{KCl}(\mathrm{pH} 1-3)$, acetic acid/sodium acetate ( $\mathrm{pH}$ 4-6), and boric acid/sodium hydroxide (7-8). pH was measured by a Metrohm 605 pH meter. A gross gamma detector (Tennelec, Canberra, Australia) equipped with an $\mathrm{NaI}(\mathrm{Tl})$ detector was used for measuring gamma counts.

\subsection{Characterization Techniques}

The morphological features of the synthesized silica adsorbents were examined by a scanning electron microscope, JSM 6490-A JEOL (Tokyo, Japan) at $20 \mathrm{kV}$. The powder silica samples were gold coated before the analysis. Energy dispersive spectroscopy (EDX) analysis was also carried out to investigate the elemental composition of the silica adsorbents.

Fourier transform infrared (FTIR) spectroscopy was used for the identification of the functional groups on the surface of the silica adsorbent. The silica powder samples were analyzed by an infrared spectrophotometer 100 of Perkin Elmer, having a resolution of $100 \mathrm{~cm}^{-1}$, using $\mathrm{KBr}$ pellets, and the samples were scanned in a wavelength range of 400 to $4000 \mathrm{~cm}^{-1}$, at a resolution of $4 \mathrm{~cm}^{-1}$. The $\% \mathrm{~T}$ (transmittance) was plotted against wavelength $\left(\mathrm{cm}^{-1}\right)$ and the structural details were determined from the spectra.

Thermogravimetric analysis (TGA) was performed to investigate the thermal stabilities of the silica adsorbents. The weight losses for all the synthesized adsorbents were recorded by a TGA analyzer using a Pyris Diamond (Perkin Elmer, Norwalk, CT, USA). The thermograms of pure and functionalized silica adsorbents were recorded in a temperature range of 30 to $700{ }^{\circ} \mathrm{C}$ in nitrogen atmosphere at a rate of $10{ }^{\circ} \mathrm{C} / \mathrm{min}$.

\subsection{Procedure of $Z n(I I)$ Adsorption}

$\mathrm{Zn}$ (II) adsorption tests were conducted in batch mode at $26 \pm 1^{\circ} \mathrm{C}$ using pre-determined optimized conditions of $0.20 \mathrm{mg}$ of functionalized silica, zinc ion concentration of $2.769 \times 10^{-4} \mathrm{M}$, 30-min equilibration time, 5-min centrifuge time at $\mathrm{pH} 7$ in a 5-mL volume. $\mathrm{Zn} \%$ uptake was calculated by using Equation (1):

$$
\% \mathrm{Zn}(\mathrm{II}) \text { adsorption }=\frac{A_{0}-A_{e}}{A_{0}}
$$

where $A_{0}$ and $A_{\mathrm{e}}$ represent the initial and equilibrium concentration of zinc, respectively. The distribution coefficient $\left(K_{\mathrm{D}}\right)$ was determined by using Equation (2):

$$
K_{D}=\frac{\text { quntity of } \mathrm{Zn}(\mathrm{II}) \text { adsorbed }}{\text { quntity of } \mathrm{Zn}(\mathrm{II}) \text { in solution }} \times \frac{\text { solution volume }(V)}{\text { adsorbent mass }(W)}=\left(\frac{\mathrm{mL}}{\mathrm{g}}\right)
$$

\subsection{Synthesis of Grafted Silica}

Silica and amine-functionalized silica nanospheres were prepared as reported earlier [22]. For synthesizing thiosemicarbazide silica, $5 \mathrm{~g}$ of ligand were suspended in $50 \mathrm{~mL}$ of de-ionized water in a flask and placed on a hot plate. In total, $30 \mathrm{~mL}$ of formaldehyde (37\%) were added drop wise and refluxed for one hour, then $10 \mathrm{~g}$ of the pre-synthesized amine-functionalized silica were added to it and refluxed for half hour. The thiosemicarbazide silica was filtered and washed with distilled water, ethanol, and methanol to eliminate the un-reacted reagents and in a tube furnace at $50{ }^{\circ} \mathrm{C}$ for one hour. 


\subsection{DFT Simulations}

The molecular simulations were performed on Gaussian 09 code [21] using B3LYP theory and 6-31 G (d,p) basis set for $C, H, N$, and $S$ atoms by selecting LANL2DZ basis set for the Zn atom. The frequency calculations were performed using the same theory and basis set to obtain thermochemical parameters at $298.15 \mathrm{~K}$ and $1 \mathrm{~atm}$ to check whether the geometries were at local minima or not. The absence of an imaginary frequency confirmed that all the geometries were at local minima. Explicitly solvent effects (addition of water molecules) were used. The contribution of electrostatic effects to the binding energies and thermodynamic data were computed by employing the conductor-like polarizable continuum model (CPCM) [23,24]. The binding energies both in gas and solvent phases were computed by:

$$
B E=E_{\text {Complex }}-E_{\left(\mathrm{FG}+\left[\mathrm{Zn}\left(\mathrm{H}_{2} \mathrm{O}\right)_{6}\right]^{2+}\right)}
$$

where $E_{\text {Complex }}$ is the total energy of the complex system (metal attached with FG) and $E_{\left(\mathrm{FG}+\left[\mathrm{Zn}\left(\mathrm{H}_{2} \mathrm{O}\right)_{6}\right]^{2+}\right)}$ is the energy of the individual monomer (FG and $\left.\left[\mathrm{Zn}\left(\mathrm{H}_{2} \mathrm{O}\right)\right]^{2+}\right)$. The change in enthalpy $(\Delta H)$ and free energy $(\Delta H)$ were also calculated:

$$
\begin{gathered}
\Delta H_{a d}=H_{\text {Complex }}-H_{\left(\mathrm{FG}+\left[\mathrm{Zn}\left(\mathrm{H}_{2} \mathrm{O}\right)_{6}\right]^{2+}\right)} \\
\Delta G_{a d}=\Delta H_{a d}-T \Delta S_{a d} \\
\Delta G_{a d}=\Delta H_{a d}-T\left(S_{F G}+S_{\left(\mathrm{FG}+\left[\mathrm{Zn}\left(\mathrm{H}_{2} \mathrm{O}\right)_{6}\right]^{+2}\right)}\right)
\end{gathered}
$$

where $H$ is the total electronic and thermal enthalpy, $G$ is the total electronic and thermal Gibbs free energy, and $S$ is the entropy at $298.15 \mathrm{~K}$ and $1 \mathrm{~atm}$.

\section{Results and Discussion}

\subsection{Adsorbent Characterization}

Textural properties of functionalized silica, such as pore volume, pore size, and pore diameter, were determined by the BET (Brunauer-Emmet-Teller) equation by the nitrogen gas sorption/desorption technique. The results indicated that the silica adsorbent was porous, having $920 \mathrm{~m}^{2} / \mathrm{g}$ surface area, $0.95 \mathrm{~mL} / \mathrm{g}$ of pore volume, and $4.16 \mathrm{~nm}$ pore diameter. The SEM image and EDX analysis of the prepared sample are given in Figure 1. The EDX mapping showed oxygen, sulphur, and nitrogen moieties on silica.

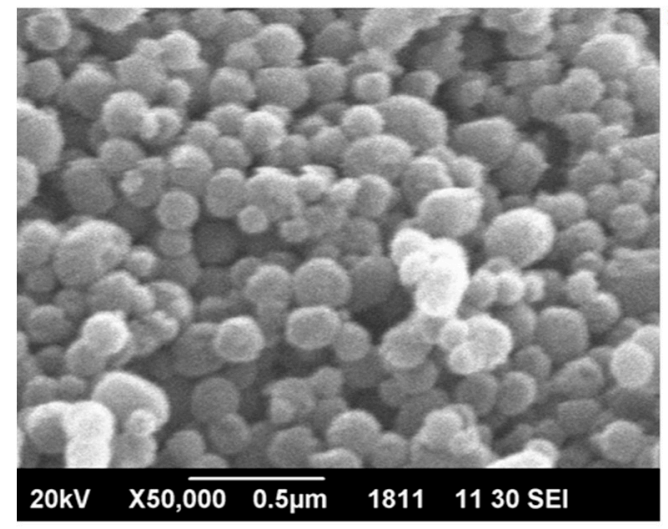

Figure 1. The SEM and EDX images of the thiosemicarbazide functionalized silica.

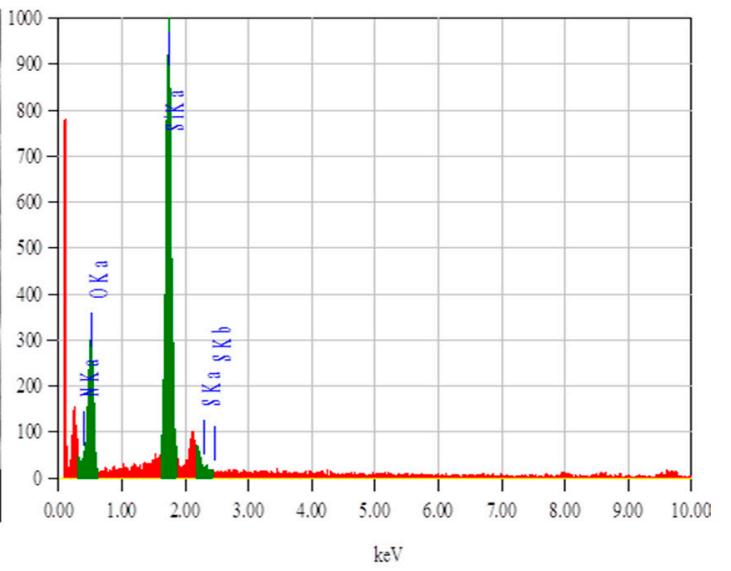

$\mathrm{keV}$ 
The FTIR analysis of the silica and thiosemicarbazide functionalized silica is given in Figure 2. In the plain silica, a broad band can be seen at $3437 \mathrm{~cm}^{-1}$, which is due to the silanol (Si-OH) group skeletal vibration and physisorbed water molecules. The framework siloxane group (Si-O-Si) vibration occurred at $1114.0 \mathrm{~cm}^{-1}$. The stretching and bending vibrations (symmetric) of the siloxane groups appeared at 601.0 and $476.0 \mathrm{~cm}^{-1}$. After functionalization, some new groups appeared at 1344.0 and $1489.0 \mathrm{~cm}^{-1}$; these groups were ascribed to $-\mathrm{N}-\mathrm{H}-\mathrm{C}=\mathrm{S}$ vibration [20]. The expected vibration of the $-S=C$ - group at 730.0 to $1089 \mathrm{~cm}^{-1}$ was not present in our system, which might be overlapped with the strong skeletal vibration of the silica.

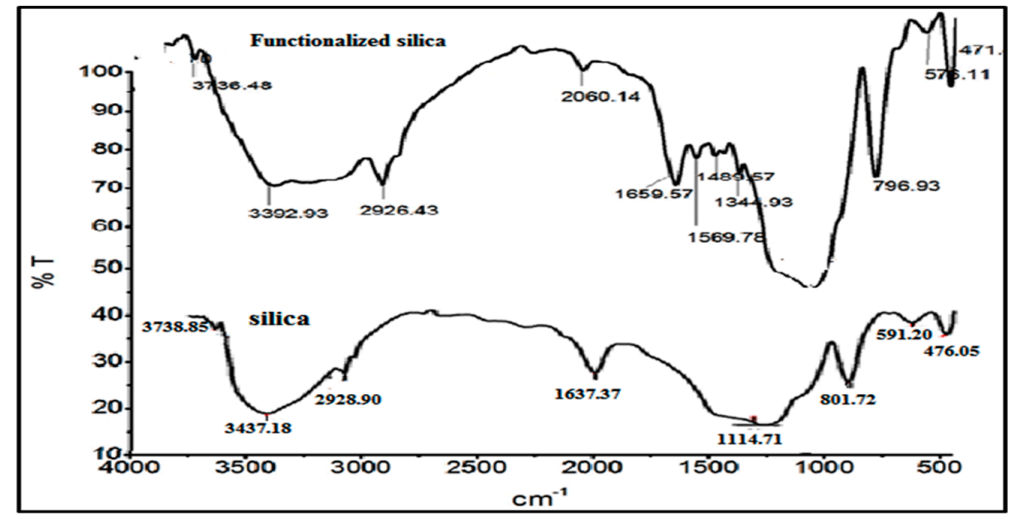

Figure 2. The FTIR analysis of the thiosemicarbazide functionalized silica.

The thermogravimetric (TGA) analysis of the synthesized functionalized silica is given in Figure 3. The functionalized silica lost its weight in three different regions. The first mass loss region was detected at a temperature of $30-250{ }^{\circ} \mathrm{C}$, which is about $3 \%$ and is due to the elimination of physisorbed surface water [25]. The second mass loss was detected at the temperature of $250-500{ }^{\circ} \mathrm{C}$ owing to the decomposition of the organic functional group ( $-\mathrm{S}=\mathrm{C}-\mathrm{NH}-)$ of the chelating ligand. The third mass loss was observed at $500-700{ }^{\circ} \mathrm{C}$, and at this temperature, the silanols are condensed to siloxane groups on the surface [26].

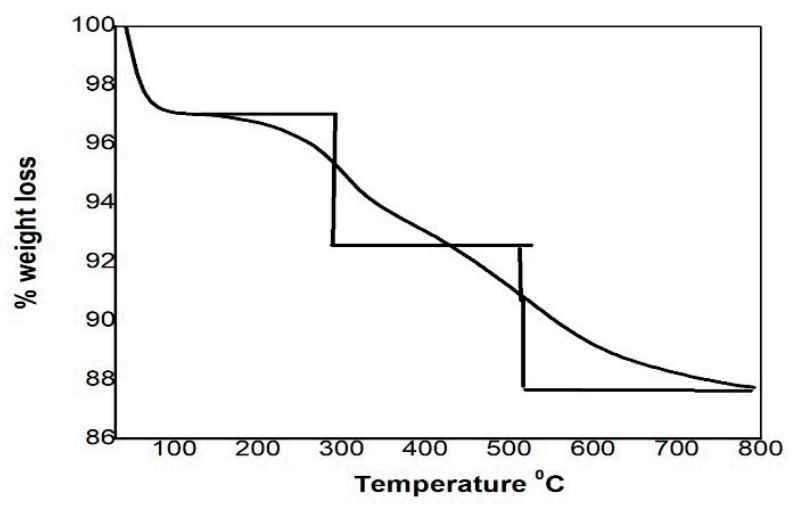

Figure 3. TGA analysis of the thiosemicarbazide functionalized silica.

\subsection{Zn(II) Adsorption on Functionalized Silica}

Medium $\mathrm{pH}$ has a key role in the removal of metal. It either protonates or deprotonates the functional groups and thus affects the functional group structure, metal speciation, and surface interactions [27]. The effect of $\mathrm{pH}$ on zinc adsorption and its distribution ( $\mathrm{K}_{\mathrm{d}}$ values) was examined in $\mathrm{pH} 1$ to $\mathrm{pH} 8$ and the outcomes are summarized in Figure 4. The $\mathrm{Zn}(\mathrm{II})$ adsorption varied with $\mathrm{pH}$ and in acidic medium (low pH), $\mathrm{Zn}$ (II) adsorption did not occur. Zinc adsorption started at $\mathrm{pH} 4$ and attained maximum (94\%) at pH 7 and then abruptly decreased. 


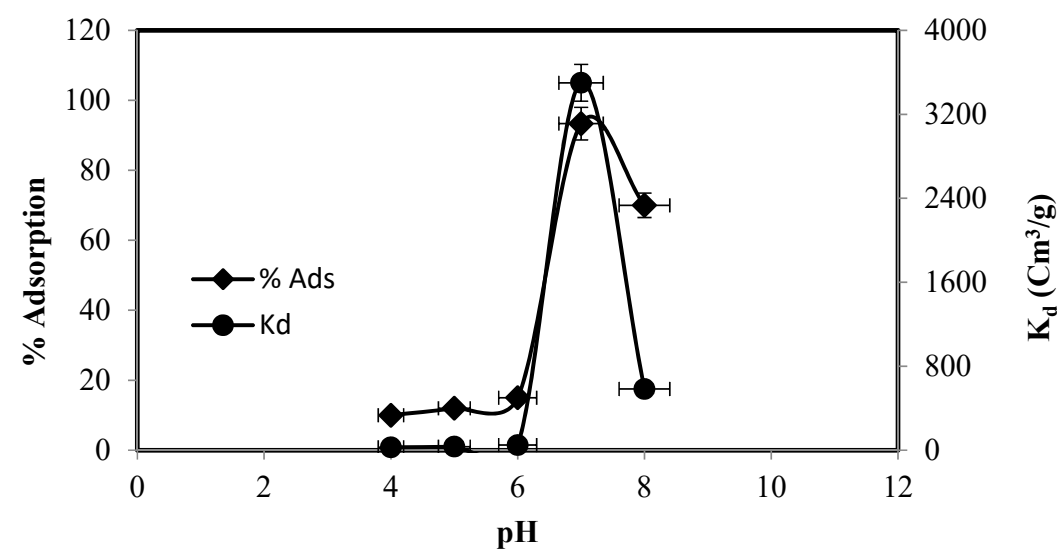

Figure 4. Effect of initial solution $\mathrm{pH}$ on the adsorption of $\mathrm{Zn}$ (II) and Kd values.

With increasing $\mathrm{pH}$, the following hydrolysis reactions of $\mathrm{Zn}^{+2}$ may occur in an aqueous system:

$$
\begin{gathered}
\mathrm{Zn}_{(\mathrm{aq})}^{+2}+\mathrm{H}_{2} \mathrm{O} \leftrightarrow \mathrm{ZnOH}^{+}+\mathrm{H}^{+}, \\
\mathrm{Zn}_{(\mathrm{aq})}^{+2}+2 \mathrm{H}_{2} \mathrm{O} \leftrightarrow \mathrm{Zn}(\mathrm{OH})_{2}+2 \mathrm{H}^{+}, \\
\mathrm{Zn}_{(\mathrm{aq})}^{+2}+3 \mathrm{H}_{2} \mathrm{O} \leftrightarrow \mathrm{Zn}(\mathrm{OH})_{3}^{-}+3 \mathrm{H}^{+}
\end{gathered}
$$

At lower $\mathrm{pH}(<6)$, zinc predominately exists as $\mathrm{Zn}^{+2}$, which coordinates to water molecules, and split to yield proton(s) and hydroxide species. The earlier researchers, on the basis of their metal speciation diagram, suggested that all the species of $\mathrm{Zn}^{2+}$ at $\mathrm{pH} 7.0$ and below carry a positive charge either as $\mathrm{Zn}^{2+}$ or $\mathrm{Zn}(\mathrm{OH})^{+}[28]$ while, at higher $\mathrm{pH}$, species like $\mathrm{Zn}(\mathrm{OH})_{3}^{-}$and precipitates of $\mathrm{Zn}(\mathrm{OH})_{2}$ may exist in solution [29]. The adsorption of zinc beyond $\mathrm{pH} 8$ was not checked due to possible precipitation and hydrolysis of the metal ions in highly basic medium. The maximum adsorption of zinc at pH 7 may possibly be due to the presence of Lewis bases, such as $\mathrm{NH}_{2^{-}},-\mathrm{NH}$, and $-\mathrm{C}=\mathrm{S}$, at $\mathrm{pH}$ 7. Lower zinc adsorption at lower $\mathrm{pH}$ may be attributed [30] to the protonation of the ligand functional groups owing to the abundance of the $\mathrm{H}^{+}$in the medium, which could interact with the surface instead of the metal ion. $\mathrm{pH} 7$ was chosen as a suitable medium for the extraction of zinc for other experiments. Figure 5 represents the possible protonation of the silica and the proposed mechanism for zinc adsorption.

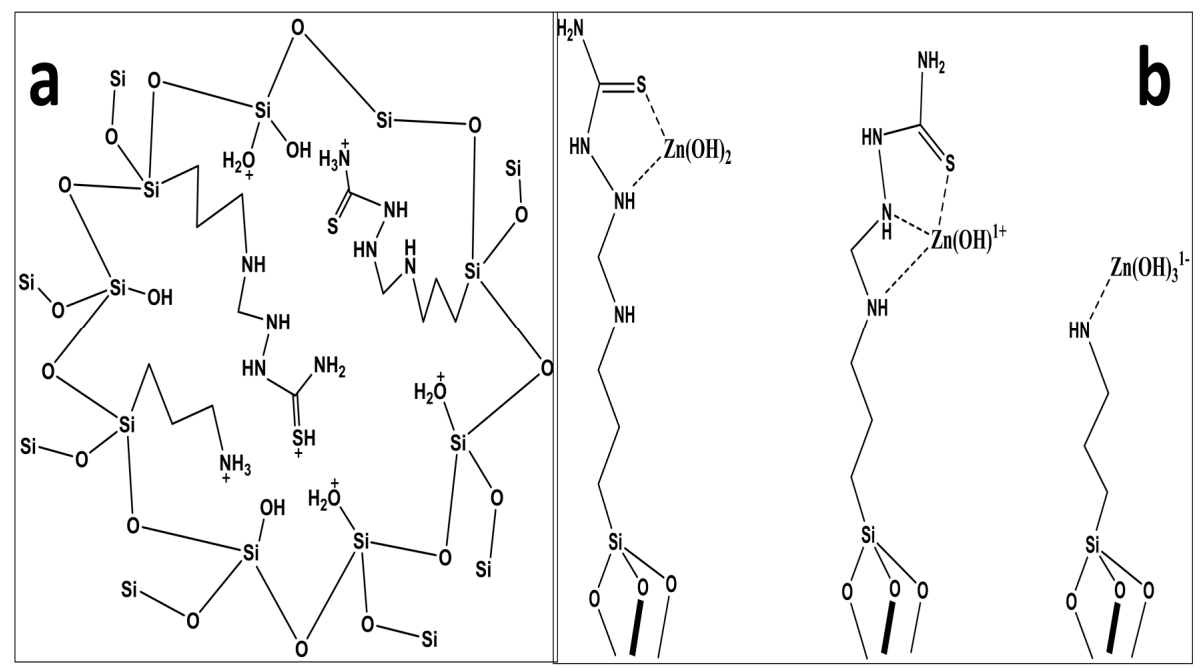

Figure 5. The possible protonation of the silica (a) and proposed mechanism for zinc adsorption (b). 
Based on the DFT simulation results, the minimized geometry of the functional group (FG), $\left[\mathrm{Zn}\left(\mathrm{H}_{2} \mathrm{O}\right)_{6}\right]^{2+}$, and $\mathrm{Zn}(\mathrm{II})$ binding with FG are depicted in Figure $6 \mathrm{a}-\mathrm{c}$ while the optimized geometrical parameters and binding energies (BEs) are given in Tables 1 and 2.

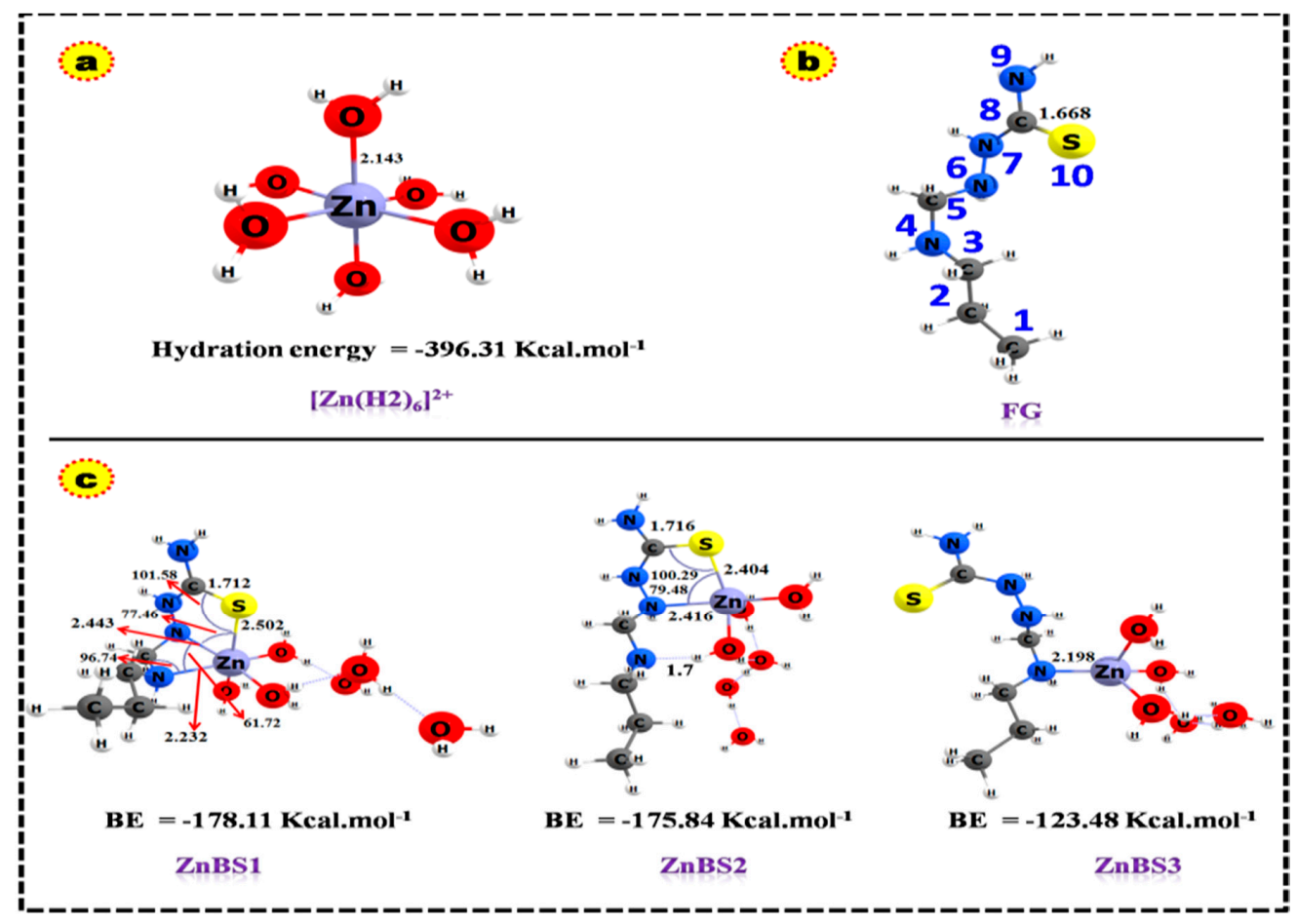

Figure 6. Optimized geometries of (a) hydrated $\left[\mathrm{Zn}\left(\mathrm{H}_{2} \mathrm{O}\right)_{6}\right]^{2+}(\mathbf{b})$ Functional group (c) complexes computed at the B3LYP level of theory and 6-31 G(d,p)/LANL2DZ basis set. All bond lengths in $\AA$.

Table 1. Optimized geometrical parameters bond lengths $(\AA)$ and angles $\left(^{\circ}\right)$ at the B3LYP/6-31 $\mathrm{G}(\mathrm{d}, \mathrm{p}) /$ LANL2DZ method.

\begin{tabular}{|c|c|c|c|c|c|c|}
\hline \multirow{2}{*}{ Specie } & \multicolumn{6}{|c|}{ Bond Lengths (£) } \\
\hline & $\mathrm{C}=\mathrm{S}$ & $\mathrm{Zn}-\mathrm{O}$ & $4 \mathrm{~N}-\mathrm{Zn}$ & $6 \mathrm{~N}-\mathrm{Zn}$ & $10 S-Z n$ & $4 \mathrm{~N} \ldots \mathrm{HO}$ \\
\hline FG & 1.67 & & & & & \\
\hline FG-Zn-1 & 1.71 & & 2.23 & 2.44 & 2.50 & \\
\hline FG-Zn-2 & 1.72 & & & 2.42 & 2.40 & 1.7 \\
\hline FG-Zn-3 & & & 2.20 & & & \\
\hline$[\mathrm{Zn}(\mathrm{H} 2 \mathrm{O}) 6]^{2+}$ & & 2.14 & & & & \\
\hline \multirow{2}{*}{ Specie } & \multicolumn{6}{|c|}{ Bond Angles ( $\left.{ }^{\circ}\right)$} \\
\hline & $5 \mathrm{C}-4 \mathrm{~N}-\mathrm{Zn}$ & $4 N-Z n-6 N$ & $6 \mathrm{~N}-\mathrm{Zn}-10 \mathrm{~S}$ & $8 C-10 S-Z n$ & $5 \mathrm{C}-4 \mathrm{~N}-\mathrm{Zn}$ & \\
\hline FG-Zn-1 & 96.74 & 61.72 & 77.46 & 101.58 & & \\
\hline FG-Zn-2 & & & 79.48 & 100.29 & & \\
\hline FG-Zn-3 & & & & & 110.7 & \\
\hline
\end{tabular}

In aqueous media, $\mathrm{Zn}$ (II) is present in a hydrated form, which contains six water molecules in the first hydration shell [31]. The explicit solvent model, which considers waters in the first-hydration shell, in conjugation with the continuum salvation model, is the most commonly used model for the balance of the hydration shell [31]. Therefore, we modelled an interaction of hydrated $\mathrm{Zn}$ (II) $\left(\left[\mathrm{Zn}\left(\mathrm{H}_{2} \mathrm{O}\right)_{6}\right]^{2+}\right)$ ion with three different sites of the function group, i.e., $\mathrm{ZnBS}$ ( $\mathrm{Zn}(\mathrm{II})$ binding to $4 \mathrm{~N}$, $6 \mathrm{~N}$ and $10 \mathrm{~S}$ ), ZnBS2 (Zn(II) binding to $6 \mathrm{~N}$ and $10 \mathrm{~S}$ ), and ZnBS3 (Zn(II) binding to $4 \mathrm{~N}$ ), as shown in 
Figure 6c. In ZnBS1 and ZnBS2, the Zn(II) binds by two and three bonds with FG, making a one and two cyclic structure. The bond length of $4 \mathrm{~N}-\mathrm{Zn}$ in cycle 1 in $\mathrm{ZnBS} 1$ is $2.23 \AA$ and the $5 \mathrm{C}-4 \mathrm{~N}-\mathrm{Zn}$ and $6 \mathrm{~N}-\mathrm{Zn}-4 \mathrm{~N}$ angles are $96.7^{\circ}$ and $61.7^{\circ}$, respectively. In cycle 2 , the $6 \mathrm{~N}-\mathrm{Zn}(\mathrm{II})$ bond length is $2.44 \AA$, making ( $6 \mathrm{~N}-\mathrm{Zn}-10 \mathrm{~S})$ an angle of $77.5^{\circ}$ while the $10 \mathrm{~S}-\mathrm{Zn}$ (II) bond length is $2.5 \AA$ and the angle (8C-10S-Zn) is $101.5^{\circ}$. The $\mathrm{C}=\mathrm{S}$ bond in ZnBS1 is stretched to $0.05 \AA$ as compared to uncovered FG. The bond length in $\mathrm{ZnBS} 2$ of $6 \mathrm{~N}-\mathrm{Zn}$ is $2.42 \AA$, making an angle of $79.5^{\circ}$ with in $6 \mathrm{~N}$ and $10 \mathrm{~S}$ atoms. Here, the $\mathrm{C}=\mathrm{S}$ bond is stretched to $0.05 \AA$ during the interaction of $10 \mathrm{~S}$ with $\mathrm{Zn}(\mathrm{II})$ ion and the angle formed in $8 \mathrm{C}-10 \mathrm{~S}-\mathrm{Zn}$ is $101.58^{\circ}$. In $\mathrm{ZnBS} 2$, the $4 \mathrm{~N}$ is not directly attached to the $\mathrm{Zn}$ (II) ion but is bonded through a hydrogen bond with the nearest water molecules $(4 \mathrm{~N}-\mathrm{HO})$, having a $1.7 \AA$ bond length and making a $163^{\circ}$ angle. The $\mathrm{Zn}$ (II) ion coordinated with FG through a coordinate covalent bond at ZnBS3 having a bond length of $2.20 \AA(4 \mathrm{~N}-\mathrm{Zn}(\mathrm{II}))$ and a bond angle of $110.7^{\circ}$. The optimized geometrical analysis suggested that zinc adsorption is more feasible at ZnBS1 than ZnBS2 and ZnBS3, making three coordinated bonds with the electronegative sites $(4 \mathrm{~N}, 6 \mathrm{~N}$, and $10 \mathrm{~S})$.

Table 2. Computed thermodynamic parameters at $298.51 \mathrm{~K}$ and $1 \mathrm{~atm}\left(\Delta E_{B E}, \Delta H_{B E}, \Delta G_{B E}\right.$ and $\left.\Delta S_{B E} \mathrm{Kcal} \cdot \mathrm{mol}^{-1}\right)$ using B3LYP theory and 6-31 G(d,p)/LANL2DZ basis sets.

\begin{tabular}{ccccccccc}
\hline Complex & \multicolumn{2}{c}{$\Delta E_{B E}$} & \multicolumn{2}{c}{$\Delta H_{B E}$} & \multicolumn{2}{c}{$\Delta G_{B E}$} & \multicolumn{2}{c}{$\Delta S_{B E}$} \\
\hline & Gas Phase & Solvent Phase & Gas Phase & Solvent Phase & Gas Phase & Solvent Phase & Gas Phase & Solvent Phase \\
\hline $\mathrm{Zn}\left(\mathrm{H}_{2} \mathrm{O}\right)_{6}$ & -396.3 & -80.91 & -394.37 & -78.91 & -362.61 & -69.43 & -218.23 & -65.31 \\
\hline $\mathrm{ZnBS1}$ & -178.11 & -59.89 & -169.82 & -57.45 & -140.76 & -49.81 & -97.46 & -51.31 \\
\hline $\mathrm{ZnBS2}$ & -175.84 & -58.90 & -168.35 & -54.71 & -140.84 & -45.72 & -92.25 & -49.10 \\
\hline $\mathrm{ZnBS3}$ & -123.48 & -41.37 & -117.77 & -40.3 & -86.66 & -37.6 & -104.34 & -54.4 \\
\hline
\end{tabular}

The binding energies were computed for various coordination modes of hydrated $\mathrm{Zn}$ (II) ion with FG using the optimized geometries and values listed in Table 2. The BEs were computed as the difference of the total energy of the reactants and products. The more negative BE energies show the stronger metal ligand interactions and highly exothermic reactions $[8,32]$. The computed BEs for all the three binding sites are negative, which indicates that the $\mathrm{ZN}$ (II)-ligand interactions are highly exothermic. The binding energies in the gas phase are higher than the solvent phase, which may be due to the strong columbic interactions between the charged-Zn(II) cation and negative functional groups [33]. The order of BEs for various binding sites is ZnBS1 $>$ ZnBS2 $>$ ZnBS3. These results demonstrate that the FG has greater affinity for Zn(II) ions on ZnBS1 and ZnBS2 than ZnBS3. The Zn(II) ion makes three coordinate bonds with the FG in ZnBS1 as discussed above, which provide more stability to the complex and therefore has higher binding energy $(\mathrm{BE}=-178.11 \mathrm{Kcal} / \mathrm{mol})$. The $\mathrm{BE}$ of ZnBS2 is not much lower $(-175.8 \mathrm{Kcal} / \mathrm{mol}$ ) than ZnBS1 (3 Kcal/mol lower), which is due to the two coordinate bonds of the $\mathrm{Zn}$ (II) ion with FG and one hydrogen bond. The additional hydrogen bond provided extra stability to the $\mathrm{Zn}$ (II) ion binding at ZnBS2, which is nearer to the ZnBS1 binding energy. While, on the other hand, the Zn(II) ion interaction in ZnBS3 is weaker than ZnBS1 and ZnBS2, having lower BE energy $(-123.4 \mathrm{kcal} / \mathrm{mol})$. The BE analysis established the fact that the more coordinated $\mathrm{Zn}$ (II) can extract the $\mathrm{Zn}(\mathrm{II})$ ions more efficiently. These results show good agreement with the previously reported work $[8,34]$. The hydration energy for $\left[\mathrm{Zn}\left(\mathrm{H}_{2} \mathrm{O}\right)_{6}\right]_{2+}$ is also listed in Table 2, which is also consistent with the reported literature [35], and the slight difference may be due to the use of a different basis set and level of theory selected. Figure 7a-i represents the molecular electrostatic potential map (MEP) of FG, natural atomic charges, and Mullikan atomic charges of FG and $\mathrm{Zn}$ (II) binding sites. The MEP map shows that the $4 \mathrm{~N}, 6 \mathrm{~N}$, and $10 \mathrm{~S}$ zones of FG are more electron-dense regions as depicted by the red color. The binding of $\mathrm{Zn}$ (II) ion is therefore more dominant on these sites. The blue region shows the electropositive region while the yellow and green zones represent the less negative and neutral regions, respectively. The variation of the Mullikan atomic charges and natural atomic charges is expressed on various atoms in Figure $7 \mathrm{~d}-\mathrm{i}$. The variance in these charges clearly depicts the charge transfer phenomena during the complex formation between the $\mathrm{Zn}(\mathrm{II})$ ion and FG. 

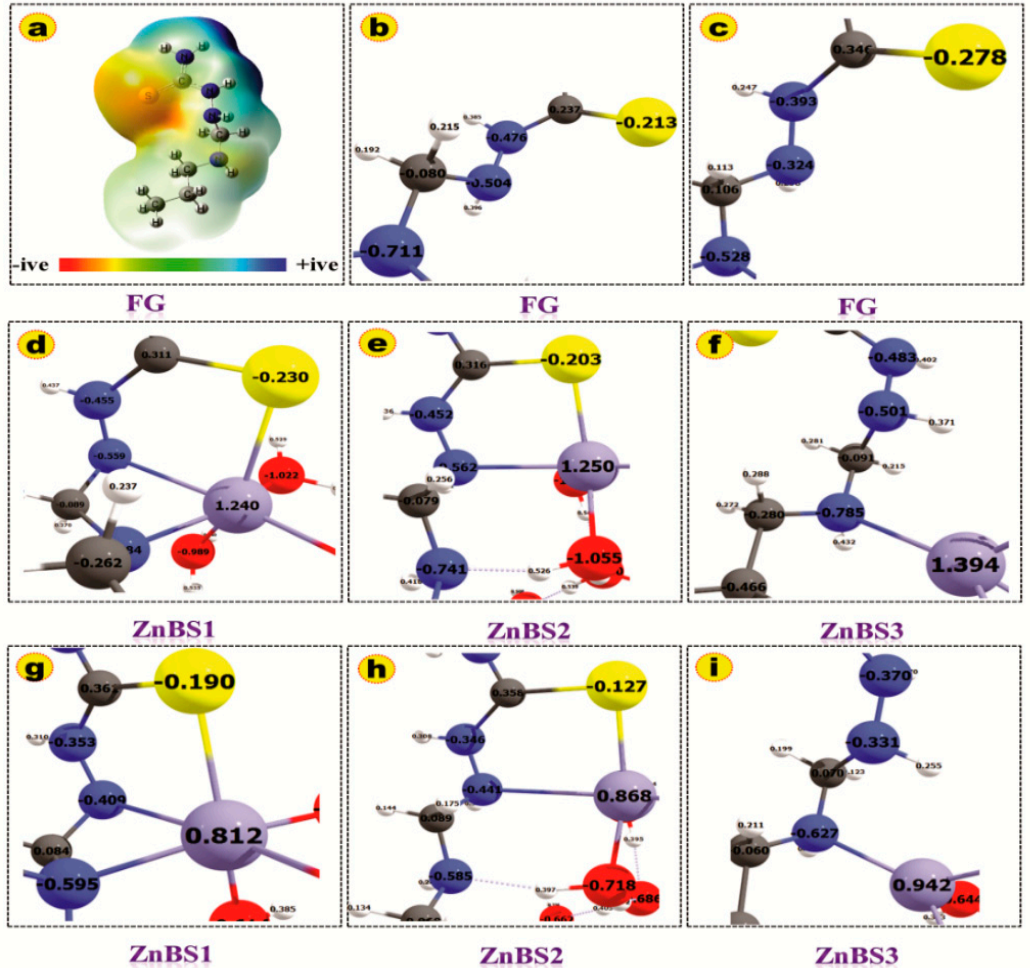

Figure 7. Computed (a) molecular electrostatic potential map; (b) NBO charges of FG; (c) Mulliken atomic charges of FG; (d) NBO charges of all complexes; (e) Mulliken atomic charges of all complexes. (f-i) Different modes of interactions of $\mathrm{Zn}$ (II) with functional groups. Only the coordinated zones are mentioned in this figure for clarity. All properties are computed in atomic unit.

The kinetic investigations were performed by equilibrating $20.0 \mathrm{mg}$ of the adsorbent, $2.769 \times 10^{-4} \mathrm{~mol} / \mathrm{L}$ of $\mathrm{Zn}$ (II) at optimized $\mathrm{pH}(\mathrm{pH} 7)$ from 5-60 min, and the results are depicted in Figure 8 . The adsorbent was recovered from the medium by centrifugation at different intervals and the solution was radio assayed for $\mathrm{Zn}$ (II) contents. In the beginning, the zinc uptake increased sharply (94\%) up to $10 \mathrm{~min}$ of agitation and then increased slowly to attain a maximum of $96 \%$ at $40 \mathrm{~min}$ of agitation time. These investigations suggested that the removal of zinc by functionalized silica is fast and around $96 \%$ of the zinc is removed in the initial $40 \mathrm{~min}$. The equilibration time is shorter, and the adsorbent has a good affinity for zinc, which could be removed quickly on its surface. The fast kinetics of zinc suggests that chemisorption may be the rate-limiting step [36].

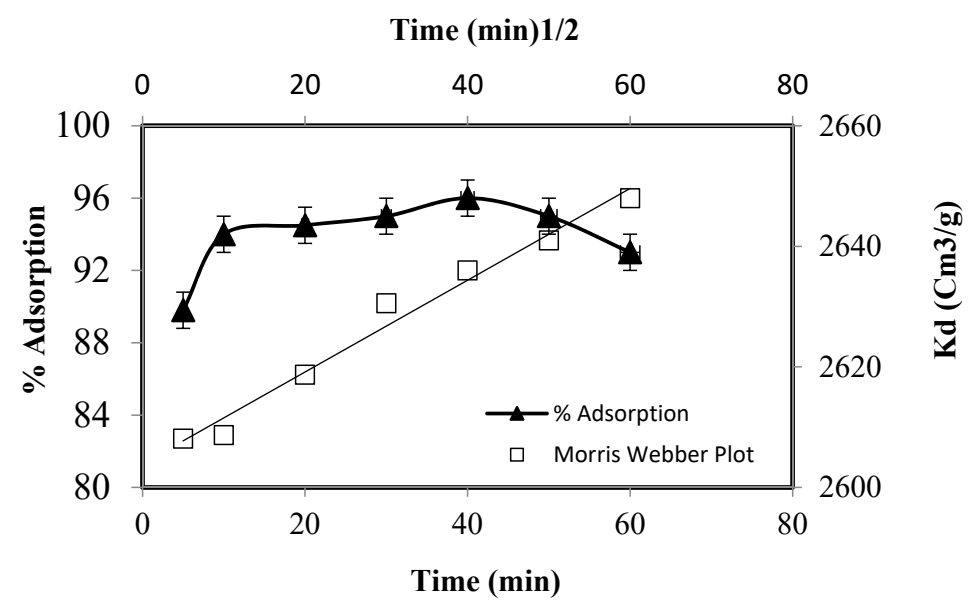

Figure 8. Adsorption of $\mathrm{Zn}(\mathrm{II})$ as a function of equilibrium time. 
The investigation of the mechanism and kinetics of adsorption is a necessary step for the application of adsorbent in industries. It has been suggested that the adsorption of metal on a solid surface is governed by film or intra particle diffusion or both of them [37]. Pertaining to the mechanism and kinetics of the zinc adsorption, the kinetic data were fitted to different rate and mass transfer equations. The Morris Webber equation was applied to investigate the film or particle diffusion nature of metal adsorption:

$$
q_{t}=R_{D} \sqrt{t}
$$

where $q_{t}$ is the amount of $\mathrm{Zn}(\mathrm{II})$ adsorbed at a given time and $R_{D}$ is the intra particle diffusion constant. Mousavi and co-workers [38] suggested that more than one adsorption steps is possible for zinc adsorption. The three possible steps are: diffusion of zinc from bulk solution onto the solid through the formation of a boundary layer, diffusion to the interior of the adsorbent, and/or $\mathrm{Zn}$ (II) adsorption on solid surface inside the pores. The final step is fast, and the adsorption of zinc is governed by the boundary layer or particle diffusion and decides the rate of zinc adsorption. Some researchers have suggested that formation of the boundary layer is the adsorption rate-determining (RDS) step [39]. The plot of $q_{t} \mathrm{v} / \mathrm{s} \sqrt{t}$ did not pass through the origin, indicating that the rate-limiting step is not controlled by particle diffusion and the adsorption mechanism is complicated, which is controlled by two or more than two adsorption steps. The kinetic adsorption data were also fed to Reichenberg's plot in the following form:

$$
F=\left(1-\frac{6}{\pi^{2}} e^{-\beta t}\right)
$$

where $F=\frac{q_{t}}{q_{e}}$ is the ratio representing the $\mathrm{Zn}(\mathrm{II})$ concentration at time ' $t$ ' and $B_{t}$ is the mathematical function. The plot of $\beta t / t \mathrm{v}$ produced a straight line, which did not pass the origin, demonstrating that the sorption is chemically controlled. The $\mathrm{Zn}(\mathrm{II})$ adsorption data were also fed to the Lagergren first-order equation:

$$
\log \left(q_{e}-q_{t}\right)=\log q_{e}-\frac{K t}{2.303}
$$

where $K$ is the first-order constant and $q_{e}$ and $q_{t}$ are the equilibrium and adsorbed concentration of $\mathrm{Zn}$ (II) on time ' $t$ '. The term $\log \left(q_{e}-q_{t}\right)$ when plotted $\mathrm{v} / \mathrm{s} t$ gave a straight line, suggesting that the $\mathrm{Zn}(\mathrm{II})$ adsorption obeys the first-order equation. The value of $K$ was $0.1020 / \mathrm{min}$.

The effect of the $\mathrm{Zn}$ (II) concentration on its adsorption was studied over a six-times increase in concentration, using $20 \mathrm{mg}$ of the functionalized adsorbent under the optimized conditions. The increase in the initial concentration increased $\mathrm{Zn}$ (II) adsorption sharply in the beginning and then became slower and attained a maximum of $94.46 \%$. At this stage, the adsorbent surface became saturated with $\mathrm{Zn}$ (II) and a further increase in concentration did not increase the zinc adsorption, indicating that adsorbent saturation depends on the initial $\mathrm{Zn}$ (II) concentration [40]. Initially, the vacant adsorbent sites are easy to be approached by $\mathrm{Zn}$ (II) ions, but later on, they need to cross the energy barrier to diffuse into the solid surface [41]. To further explore the mechanism of the $\mathrm{Zn}$ (II) adsorption, Freundlich, Langmuir, and Dubinin-Radushkevich models were applied. The modelling of the adsorption data is necessary for technological applications. These models were applied in the linear form and the various parameters computed are tabulated in Table 3.

\subsection{Zn(II) Adsorption in the Presence of Other Ions and Sorbent Regeneration}

Wastewaters generally contain co-existing ions, which affect the removal of the desired metal. The assessment of these co-existing ions is necessary as they affect the removal of the target metal. In this study, various interfering anions and cations were added to the solution matrix and their impact on $\mathrm{Zn}$ (II) adsorption was explored. For this purpose, $10 \mathrm{mg}$ of respective salt were added and its effect was investigated. The anions added, such as cyanide, oxalate, citrate, and sulphate, decreased the $\mathrm{Zn}$ (II) and some cations, such as mercury, silver, copper, and nickel, also decreased Zn(II) adsorption. On the other hand, cations, such as manganese, cadmium, lithium, iron, and EDTA, had no significant effect on zinc adsorption (Supplementary Materials). These findings revealed that this adsorbent can 
be selectively used for $\mathrm{Zn}$ (II) removal in competitive environments. The adsorbed zinc was completely recovered by treating it with 1 molar $\mathrm{HCl}$. The adsorbent was regenerated by conditioning in the pH 7 solutions and reused for extraction of zinc. Functionalized adsorbent was stable after three sorption/desorption cycles and its adsorption capacity was not altered significantly. The adsorption efficiency of the regenerated sorbent was very closer to the freshly prepared $(94.5 \%)$ sorbent up to three regenerations cycles, i.e., $94.1 \%, 94 \%$, and $94.3 \%$, respectively.

Table 3. Adsorption model constants for $\mathrm{Zn}(\mathrm{II})$.

\begin{tabular}{ccc}
\hline Isotherm Model & Constants & Values \\
\hline \multirow{3}{*}{ Langmuir isotherm } & $\mathrm{Q}\left(\mu \mathrm{mol} \mathrm{g}^{-1}\right)$ & 20,000 \\
\cline { 2 - 3 } & $\mathrm{b} \times 10^{3}\left(\mathrm{~L} \mathrm{~mol}^{-1}\right)$ & 3.8 \\
\cline { 2 - 3 } Freundlich isotherm & $1 / \mathrm{n}$ & 0.99 \\
\cline { 2 - 3 } & $\mathrm{Cm}\left(\mathrm{mmol} \mathrm{g}^{2}\right)$ & 0.1627 \\
\cline { 2 - 3 } & $\mathrm{R}^{2}$ & 1.18 \\
\cline { 2 - 3 } D-R isotherm & $\mathrm{Xm}\left(\mathrm{KJ}^{2} \mathrm{~mol}^{-2}\right)$ & 0.64 \\
\cline { 2 - 3 } & $\mathrm{Es}\left(\mathrm{KJ} \mathrm{mol} \mathrm{g}^{-1}\right)$ & -0.0015 \\
\cline { 2 - 3 } & $\mathrm{R}^{2}$ & 27.20 \\
\hline
\end{tabular}

\subsection{DFT-Based Thermodynamic Studies}

The thermodynamic study provides additional information, which helps in understanding the adsorption process [42]. In thermodynamic studies, researchers have mostly analyzed the change in enthalpy, free energy, and entropy. These thermodynamic parameters assist in the practical applications of the adsorption mechanism [43]. In the present study, we computed the thermodynamic parameters using the same level of theory and basis sets and the values are reported in Table 2 . The negative $\Delta H$ described the exothermic $\mathrm{Zn}(\mathrm{II})$ adsorption. Furthermore, if the $\Delta \mathrm{H}$ values for $\mathrm{Zn}(\mathrm{II})$ ion adsorption are more than $10 \mathrm{Kcal} / \mathrm{mol}$, the adsorption is chemical and vice versa [42,43]. The computed values of $\Delta H$ for all different sites are highly negative, which proved the exothermic and chemisorption process. The values of the calculated $\Delta S$ are negative, describing the lesser disorder at the solid-liquid interface. The tabulated values of $\Delta G$ are negative for all binding sites, which evidenced the feasible and spontaneous $\mathrm{Zn}(\mathrm{II})$ adsorption. The more negative $\Delta \mathrm{G}$ suggested the more negative BE, which showed higher $\mathrm{Zn}(\mathrm{II})$ adsorption on the modified silica surface and that the reaction is spontaneous at low temperatures.

\section{Conclusions}

This study reported the fabrication of functionalized silica adsorbent and its successful application for the extraction of zinc. The adsorbent was used for $\mathrm{Zn}$ (II) extraction in batch operations using the radiotracer technique. The adsorbent can remove about $94.5 \%$ of $\mathrm{Zn}$ (II) ions at $\mathrm{pH}=7$, near zero point charge $(\mathrm{pHzpc}=6.5)$ of the adsorbent in $40 \mathrm{~min}$ of equilibration. The zinc adsorption is dominated by particle diffusion and follows the first-order equation with $K=0.1020 / \mathrm{min}$. The Freundlich, Langmuir, and D-R isotherms were followed over a good range of $\mathrm{Zn}(\mathrm{II})$ concentration. The adsorbent can be selectively used for zinc extraction in the presence of other ions. The $\mathrm{Zn}$ (II) adsorbed can be recovered and the adsorbent can be reconditioned by treatment with $1.0 \mathrm{M} \mathrm{HCl}$ solution. In addition, DFT analysis showed that the zinc is greatly adsorbed on the silica surface by making strong coordinated bonds with $\mathrm{N}$ and $\mathrm{S}$ atoms of functional groups. The binding energy value for ZnBS1 is higher $(-178.1 \mathrm{Kcal} / \mathrm{mol})$, suggesting the stronger adsorption of $\mathrm{Zn}$ (II) ions. The higher negative $\Delta H$ values of $\mathrm{Zn}$ (II) ion 
adsorption indicate the exothermic and chemisorption process. The negative $\Delta G$ values confirmed that the adsorption of $\mathrm{Zn}(\mathrm{II})$ ions on functionalized silica is a spontaneous process.

Supplementary Materials: The following are available online at Table S1: Effect of anions on the sorption of $\mathrm{Zn}$ (II) $\left(2.769 \times 10^{-4} \mathrm{M}\right)$ on to TCS functionalized nano silica, silica $(20 \mathrm{mg})$ after $30 \mathrm{~min}$ agitation time and $\mathrm{pH} 7.0$, Table S2: Effect of cations on the sorption of $\mathrm{Zn}(\mathrm{II})\left(2.769 \times 10^{-4} \mathrm{M}\right)$ on to TCS functionalized nano silica, $(20 \mathrm{mg})$, agitation time $30 \mathrm{~min}$ and $\mathrm{pH}$ 7.0.

Author Contributions: Z.A. carried out all the experimental work in laboratory and played a major role in the writing and organization of the manuscript; R.A. and W.A.F. Supervised the progress of the research work and helped in the organization and interpretation of the data; A.K. and M.A.A. planed the research activity and was actively involved in the progress of the research work and interpretation of the data; A.A.K. carried out all the computer simulation experiment and explained the computational data; S.B. and M.A. helped in the manuscript preparation and data analysis; B.A. and N.Y. helped the corresponding author in the analysis, interpretation and organization of data. All authors have read and agreed to the published version of the manuscript.

Funding: The APC was funded by the project No RG-1435-059 from King Saud University.

Acknowledgments: The authors would like to extend their sincere appreciation to the Deanship of Scientific Research at King Saud University for its funding of this research through the Research Group Project no. RG-1435-059.

Conflicts of Interest: The authors declare no conflict of interest.

\section{References}

1. He, Y.; Liu, Q.; Hu, J.; Zhao, C.; Peng, C.; Yang, Q.; Wang, H.; Liu, H. Efficient removal of Pb (II) by amine functionalized porous organic polymer through post-synthetic modification. Sep. Purif. Technol. 2017, 180, 142-148. [CrossRef]

2. Mahmud, H.N.M.E.; Huq, A.O.; Binti Yahya, R. The removal of heavy metal ions from wastewater/aqueous solution using polypyrrole-based adsorbents: A review. RSC Adv. 2016, 6, 14778-14791. [CrossRef]

3. Hao, S.; Verlotta, A.; Aprea, P.; Pepe, F.; Caputo, D.; Zhu, W. Optimal synthesis of Amino functionalized mesoporous silicas for the adsorption of heavy metal ions. Micropor. Mesopor. Mater. 2016, 236, 250-259. [CrossRef]

4. Sather, A.C.; Berryman, O.B.; Rebek, J., Jr. Selective recognition and extraction of the uranyl ion. J. Am. Chem. Soc. 2010, 132, 13572-13574. [CrossRef] [PubMed]

5. Hou, H.; Yu, D.; Hu, G. Preparation and properties of ion-imprinted hollow particles for the selective adsorption of silver ions. Langmuir 2015, 31, 1376-1384. [CrossRef]

6. Bhatnagar, A.; Vilar, V.J;; Botelho, C.M.R.; Boaventura, A. A review of the use of red mud as adsorbent forthe removal of toxic pollutants from water and wastewater. Environ. Technol. 2011, 32, 231-249. [CrossRef]

7. Aljerf, L. efficiency extraction of bromocresol purple dye and heavy metals as chromium from industrial effluent by adsorption onto a modified surface of zeolite: Kinetics and equilibrium study. J. Environ. Manag. 2018, 225, 120-132. [CrossRef]

8. Tao, H.C.; Zhang, H.R.; Li, J.B.; Ding, W.Y. Biomass based activated carbon obtained from sludge and sugarcane bagasse for removing lead ion from wastewater. Bioresour. Technol. 2015, 192, 611-617. [CrossRef]

9. Nayak, A.; Bhushan, B.; Gupta, V.; Sharma, P. Chemically activated carbon from lignocellulosic wastes for heavy metal wastewater remediation: Effect of activation conditions. J. Colloid Interface Sci. 2017, 493, 228-240. [CrossRef]

10. Tavakoli, O.; Goodarzi, V.; Saeb, M.R.; Mahmoodi, N.M.; Borja, R. Competitive removal of heavy metal ions from squid oil under isothermal condition by CR11 chelate ion exchanger. J. Hazard. Mater. 2017, 334, 256-266. [CrossRef]

11. Samiey, B.; Cheng, C.H.; Wu, J. Organic-inorganic hybrid polymers as adsorbents for removal of heavy metal ions from solutions: A review. Materials 2014, 7, 673-726. [CrossRef] [PubMed]

12. Mahmoud, M.E.; Hafez, O.F.; Alrefaay, A.; Osman, M.M. Performance evaluation of hybrid inorganic/organic adsorbents in removal and preconcentration of heavy metals from drinking and industrial waste water. Desalination 2010, 253, 9-15. [CrossRef] 
13. Soylak, M.; Unsal, Y.E. Chromium and iron determinations in food and herbal plant samples by atomic absorption spectrometry after solid phase extraction on single-walled carbon nanotubes (SWCNTs) disk. Food Chem. Toxicol. 2010, 48, 1511-1515. [CrossRef] [PubMed]

14. Sierra, I.; Pérez-Quintanilla, D. Heavy metal complexation on hybrid mesoporous silica: An approach to analytical applications. Chem. Soc. Rev. 2013, 42, 3792-3807. [CrossRef]

15. World Health Organization. Guidelines for Drinking-Water Quality, 4th ed.; World Health Organization: Geneva, Switzerland, 2011.

16. Shafiabadi, M.; Dashti, A.; Tayebi, H.A. Removal of Hg (II) from aqueous solution using polypyrrole/SBA-15 nanocomposite: Experimental and modeling. Synth. Metals 2016, 212, 154-160. [CrossRef]

17. Ahmad, R.; Ahmed, M. Removal of $\mathrm{Zn}(\mathrm{II})$ ions from aqueous solutions using BPHA-impregnated polyurethane foam. J. Chin. Chem. Soc. 2008, 55, 147-154. [CrossRef]

18. Yang, H.; Xu, R.; Xue, X.; Li, F.; Li, G. Hybrid surfactant-templated mesoporous silica formed in ethanol and its applications for heavy metal removal. J. Hazard. Mater. 2008, 152, 690-698. [CrossRef]

19. Hossain, K.Z.; Mercier, L. Intra frame work metal ion adsorption in ligand functionalized mesoporous silica. Adv. Mater. 2002, 14, 1053-1056. [CrossRef]

20. Pérez-Quintanilla, D.; Sánchez, A.; del Hierro, I.; Fajardo, M.; Sierra, I. Preparation, characterization, and $\mathrm{Zn}^{2+}$ adsorption behavior of chemically modified MCM-41 with 5-mercapto-1-methyltetrazole. J. Colloid Interface Sci. 2007, 313, 551-562. [CrossRef]

21. Frisch, M.; Trucks, G.; Schlegel, H.; Scuseria, G.; Robb, M.; Cheeseman, J.; Scalmani, G.; Barone, V.; Mennucci, B.; Petersson, G.; et al. Gaussian 09, Revision A. 02; Gaussian Inc.: Wallingford, CT, USA, 2009; pp. 1372-1377.

22. Heidari, A.; Younesi, H.; Mehraban, Z. Removal of $\mathrm{Ni}$ (II), Cd (II), and Pb (II) from a ternary aqueous solution by amino functionalized mesoporous and nano mesoporous silica. Chem. Eng. J. 2009, 153, 70-79. [CrossRef]

23. Marenich, A.V.; Cramer, C.J.; Truhlar, D.G. Universal Solvation Model Based on Solute Electron Density and on a Continuum Model of the Solvent Defined by the Bulk Dielectric Constant and Atomic Surface Tensions. J. Phys. Chem. B 2009, 113, 6378-6396. [CrossRef] [PubMed]

24. Arakaki, L.; Filha, V.A.; Germano, A.; Santos, S.; Fonseca, M.; Sousa, K.; Espínola, J.; Arakaki, T. Silica gel modified with ethylenediamine and succinic acid-adsorption and calorimetry of cations in aqueous solution. Thermochim. Acta. 2013, 556, 34-40. [CrossRef]

25. Arce, V.B.; Scotto, J.; Allegretti, P.E.; Melo, M.A., Jr.; Airoldi, C.; Salum, M.L.; Erra-Balsells, R.; Pis Diez, R.; Mártire, D.O. Combined experimental and computational investigation of the fluorescence quenching of riboflavin by cinnamic alcohol chemisorbed on silica nanoparticles. J. Phys. Chem. C 2014, 118, 15348-15355. [CrossRef]

26. Sakkayawong, N.; Thiravetyan, P.; Nakbanpote, W. Adsorption mechanism of synthetic reactive dye wastewater by chitosan. J. Colloid Interface Sci. 2005, 286, 36-42. [CrossRef] [PubMed]

27. Akhavan, B.; Jarvis, K.; Majewski, P. Plasma Polymer Functionalized Silica Particles for Heavy Metals Removal. ACS App. mater. Interfaces 2015, 7, 4265-4274.

28. De Zoubov, N.; Pourbaix, M. Atlas of Electrochemical Equilibria in Aqueous Solutions; Pourbaix, M., Ed.; National Association of Corrosion Engineers; Ceberlcor: Houston, TX, USA, 1966; pp. 406-413.

29. Kaya, A.; Ören, A.H. Adsorption of Zinc from Aqueous Solutions to Bentonite. J. Hazard. Mater. 2005, 125, 183-189. [CrossRef]

30. Algarra, M.; Jiménez, M.V.; Rodríguez-Castellón, E.; Jiménez-López, A.; Jiménez-Jiménez, J. Heavy metals removal from electroplating wastewater by aminopropyl-Si MCM-41. Chemosphere 2005, 59, 779-786. [CrossRef]

31. Xie, X.; Tian, Y.; Qin, Z.; Yu, Q.; Wei, H.; Wang, D.; Li, X.; Wang, X. Complexation of Manganese with Glutarimidedioxime: Implication for Extraction Uranium from Seawater. Sci. Rep. 2017, 7, 43503. [CrossRef]

32. Niu, Y.; Yang, J.; Qu, R.; Gao, Y.; Du, N.; Chen, H.; Sun, C.; Wang, W. Synthesis of Silica-Gel-Supported Sulfur-Capped PAMAM Dendrimers for Efficient $\mathrm{Hg}(\mathrm{II})$ Adsorption: Experimental and DFT Study. Ind. Eng. Chem. Res. 2016, 55, 3679-3688. [CrossRef]

33. Remko, M.; Broer, R.; Remková, A.; Duijnen, P.T.V. How strong are $\mathrm{Ca}^{2+}$-heparin and $\mathrm{Zn}^{2+}-$ heparin interactions? Chem. Phys. Lett. 2015, 621, 12-17. [CrossRef] 
34. Carreño, A.; Schott, E.; Zarate, X.; Manriquez, J.M.; Vega, J.C.; Mardones, M.; Cowley, A.H.; Chavez, I.; Hinestroza, J.P.; Arratia-Perez, R. DFT studies on coordination models for adsorption essays of $\mathrm{Cu}(\mathrm{II})$ and $\mathrm{Ni}(\mathrm{II})$ solutions in modified silica gel with iminodiacetic groups. Chem. Pap. 2017, 71, 1019-1030. [CrossRef]

35. Hartmann, M.; Clark, T.; Eldik, R. Hydration and Water Exchange of Zinc(II) Ions. Application of Density theory. J. Am. Chem. Soc. 1997, 119, 7843-7850. [CrossRef]

36. Melo, D.Q.; Neto, V.O.; Oliveira, J.T.; Barros, A.L.; Gomes, E.C.; Raulino, G.S.; Longuinotti, E.; Nascimento, R.F. Adsorption equilibria of $\mathrm{Cu}^{2+}, \mathrm{Zn}^{2+}$, and $\mathrm{Cd}^{2+}$ on EDTA-functionalized silica spheres. J. Chem. Eng. Data 2013, 58, 798-806. [CrossRef]

37. Dabrowski, A. Adsorption-From theory to practice. Adv. Colloid Interface Sci. 2001, 93, 135-224. [CrossRef]

38. Mousavi, S.J.; Parvini, M.; Ghorbani, M. Experimental design data for the zinc ions adsorption based on Mesoporous modified chitosan using Central Composite Design method. Carbohydr. Polym. 2018, 188, 197-212. [CrossRef]

39. Singh, K.; Mohan, S. Kinetic studies of the sucrose adsorption onto an alumina interface. App. Surf. Sci. 2004, 221, 308-318. [CrossRef]

40. Hanif, M.A.; Nadeem, R.; Bhatti, H.N.; Ahmad, N.R.; Ansari, T.M. Ni(II) bio sorption by Cassia fistula (Golden Shower) biomass. J. Hazard Matter. 2007, 139, 345-355. [CrossRef]

41. Quintelas, C.; Rocha, Z.; Silva, B.; Fonseca, B.; Figueiredo, H.; Tavares, T. Removal of Cd (II), Cr (VI), Fe (III) and $\mathrm{Ni}$ (II) from aqueous solutions by an E. coli biofilm supported on kaolin. Chem. Eng. J. 2009, 149, 319-324. [CrossRef]

42. Tran, L.; Wu, P.; Zhu, Y.; Liu, S.; Zhu, N. Comparative study of Hg(II) adsorption by thiol- and hydroxyl-containing bifunctional montmorillonite and vermiculite. App. Surf. Sci. 2015, 356, 91-101. [CrossRef]

43. Liu, Y.; Gao, M.; Gu, Z.; Luo, Z.; Ye, Y.; Lu, L. Comparison between the removal of phenol and catechol by modified montmorillonite with two novel hydroxyl-containing Gemini surfactants. J. Hazard. Mater. 2014, 267, 71-80. [CrossRef]

Sample Availability: Samples of the compounds are available from the authors.

Publisher's Note: MDPI stays neutral with regard to jurisdictional claims in published maps and institutional affiliations.

(C) 2020 by the authors. Licensee MDPI, Basel, Switzerland. This article is an open access article distributed under the terms and conditions of the Creative Commons Attribution (CC BY) license (http://creativecommons.org/licenses/by/4.0/). 